\section{Early Career Investigator}

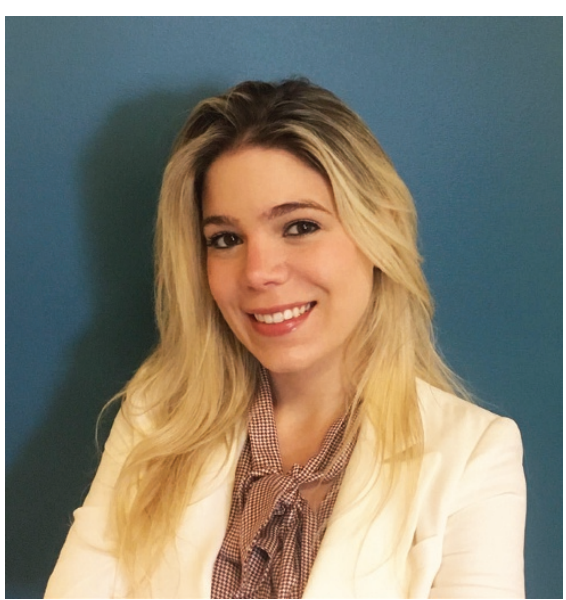

Congratulations to Raissa Nobrega, February's Early Career Investigator. Her Commentary explains how her early life experiences shaped the choice of her career and describes her exciting upcoming anesthesiology residency. Also in this issue, she and her colleagues report how the concomitant use of ketamine with opioids in managing the pain of vasoocclusive episodes from sickle cell disease reduced both pain scores and the amount of opioids needed for pain control. See pages 400 and 445

\section{History of the beliefs surrounding birth asphyxia}

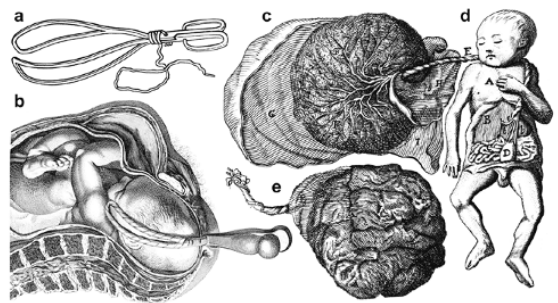

In this fascinating review, Michael Obladen discusses historical shifts in theories surrounding birth asphyxia. Beginning the story with ancient history, Dr Obladen notes that asphyxia was considered an unavoidable fate. However, in the late seventeenth century, the understanding of the cause turned to a respiratory problem with the placenta, something that could be prevented. The conflict between midwives and surgeons led to a culture of blame and the effectiveness of interventions that have not been confirmed. See page 403

\section{Response biomarkers in neonatal trials}

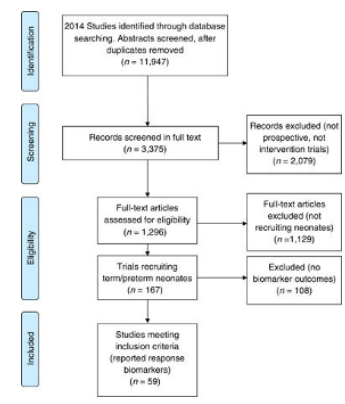

The push to develop and test new drugs in neonates has made it even more important to develop biomarkers of the treatment outcomes. Kelly et al. reviewed literature on neonatal intervention studies published in 2014. They found wide variability in the biomarkers used and how they were reported. The authors call for reporting initiatives to improve the use of biomarkers. See page $\mathbf{4 2 5}$

\section{Using growth velocity to target genetic screening for SHOXD}

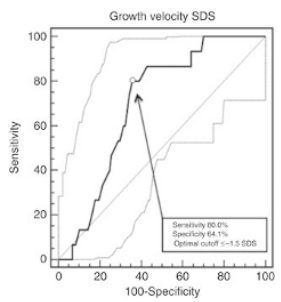

In this very interesting paper, Genoni et al. show that growth velocity can be used as a first-tier screen to identify children at higher risk for a short stature homeobox containing gene deficiency (SHOXD) mutation as a cause of their short stature. Using this initial screen improves the sensitivity and specificity of the genetic test. See page 438

\section{Using NIRS to detect brain edema}

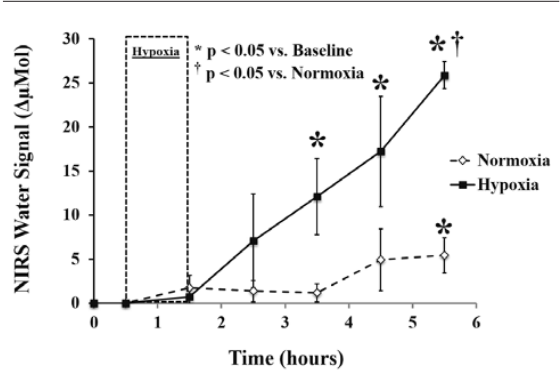

Using a piglet model, Malaeb et al. demonstrated the utility of using near-infrared spectroscopy (NIRS) to detect brain edema. Changes in signal strength occurred within 2 hours after hypoxia, and correlated with both cerebral water content and aquaphorin levels. See page 484

\section{Age-dependent differences in expression and functional activity of CYPs and FOMs}

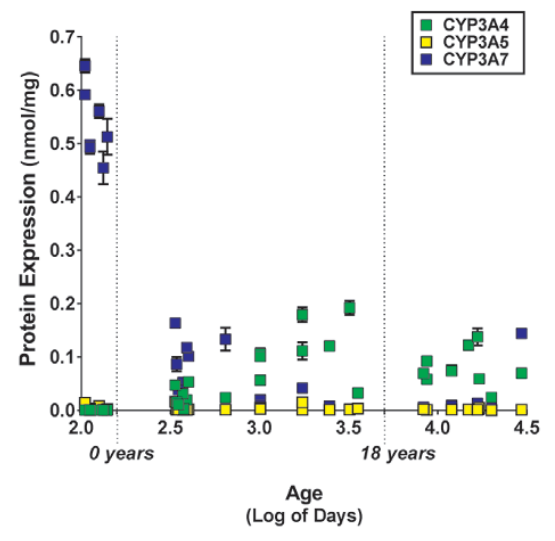

The expression and activity of the cytochrome P450 (CYP) and flavincontaining monooxygenase (FOM) enzymes are important for changes in drug metabolism, and hence dosing. Zane et al. obtained fetal, pediatric, and adult liver samples to investigate the changes in the CYP and FOM enzymes. The surprising finding is that functional activity may be higher than that predicted by protein level.

See page 527 